\title{
JOURNAL.RU
}

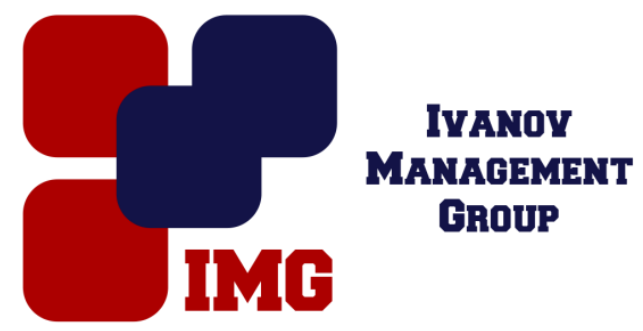

Бикжанов О.З., Кубеков А.В., Мальцева Н.С., Барабанова Е.А., Мальцев Д.Б. Астраханский Государственный Технический Университет Астрахань, Россия

doi: $10.18411 / 1 \mathrm{j}-30-06-2017-14$

idsp 000001:1j-30-06-2017-14

\section{Увеличение производительности сети передачи данных за счет изменения характеристик сети}

\begin{abstract}
Аннотация
Рассматривается производительность сети передачи данных, влияние характеристик коммутационной системы на нее. C помощью методики аналитического моделирования были рассчитаны дополнительные характеристики, такие как: интенсивность обслуживания, среднее время ожидания пакетов и размер буфера коммутационного устройства, а также коэффициент загрузки сети. Было определено, что при увеличении коэффициента загрузки сети, увеличивается среднее время ожидания и средняя длина очереди, а при увеличении размера буфера, увеличивается среднее время задержки и уменьшается вероятность потерь.

Ключевые слова: источник трафика, обрабатывающее устройство, буфер, потребитель трафика, аналитическое моделирование.

В сетях передачи данных могут возникнуть проблемы с отправкой информации, которые приводят к появлению очереди из неотправленных данных. Такое случается тогда, когда скорость передачи трафика становится меньше максимальной скорости его формирования.

Какая бы ни была хорошая эффективная ширина полосы пропускания, предоставляемая пользователю, на узле Интернет-провайдера могут появиться задержки, которые обусловлены случайными процессами в сети. Потому особенно важно получить значения ширины полосы пропускания. Но этих
\end{abstract}


данных все равно мало для хорошего качества. Поэтому имеется необходимость рассчитать дополнительные характеристики, такие как: интенсивность обслуживания, среднее время ожидания пакетов и размер буфера коммутационного устройства, а также коэффициент загрузки сети, которые тоже, в свою очередь, зависит от качества сервиса.

Оценим вышеперечисленные параметры трафика с помощью аналитического моделирования.

\section{Аналитическое моделирование.}

Разберем процесс передачи данных по сети Ethernet:

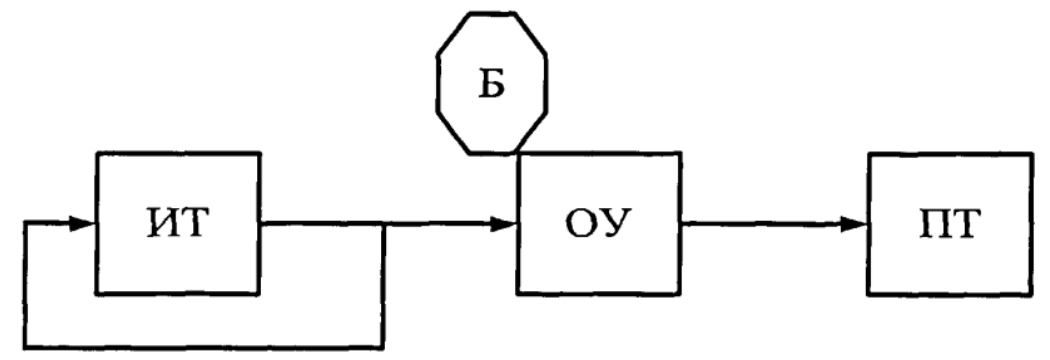

Рис. 1. Структурная схема процесса передачи данных по сети Ethernet

Такая система называется системой типа $\mathrm{M} / \mathrm{G} / 1$, в которой входной процесс определяется распределением Пуассона со скоростью поступления пакетов $\lambda$ и интенсивностью обслуживания $\mu$ [4].

Введем обозначения:

п - номер пакета;

$\mathrm{Xn}$ - его время ожидания в очереди;

Yn - длительность обработки этого пакета;

$\mathrm{Zn}$ - интервал времени между поступлениями n и n +1 пакета.

От источника трафика (ИТ) на вход обрабатывающего устройства (ОУ) проходит поток пакетов, описывающийся двумя случайными величинами: интервалом времени между поступлениями пакетов $\mathrm{Zn}$ и размером пакета $\mathrm{Ln}$. Время обработки Yn напрямую зависит от размера пакета Ln. Буфер (Б) функционирует по схеме FIFO и имеет очередь из пакетов, которые ожидают обработки в ОУ. Потребитель трафика (ПТ) в данном случае является нагрузкой.

В кадр Ethernet входят преамбулы (служит для синхронизации передатчика и приемника физического уровня), служебные информации, полезные нагрузки и контрольные суммы (рисунок 2). Размер преамбулы в дуплексном режиме зафиксирован в 64 бита, а служебной информации в 112 бит. Контрольная сумма составляет 32 бита. Полезная нагрузка - это величина переменная и лежит в диапазоне [368,12000] бит [10]. 
Таким образом Ln определена на битовом отрезке $[512,12144]$ бит.

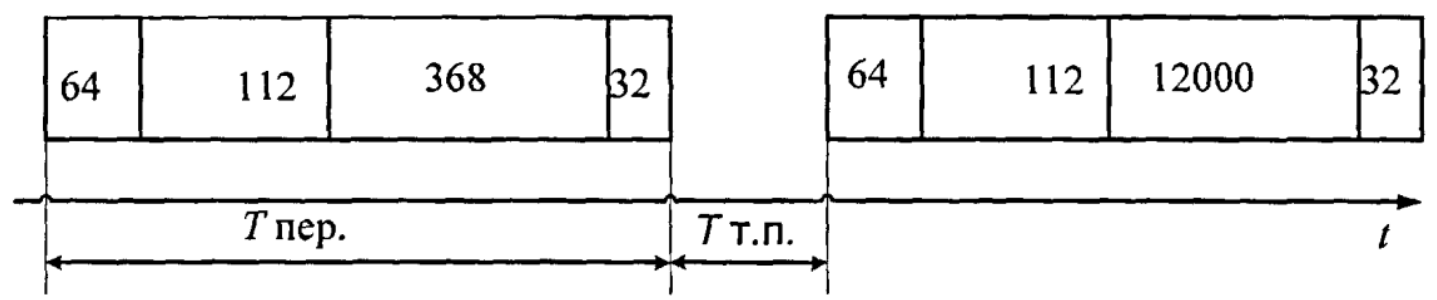

Puc. 2. Формат кадра Ethernet

Передача кадра в канале состоит из двух фаз: первая фаза - это межкадровая пауза (p-), вторая фаза - передача кадра (p+). Представим процесс передачи кадров в виде функциональной диаграммы:

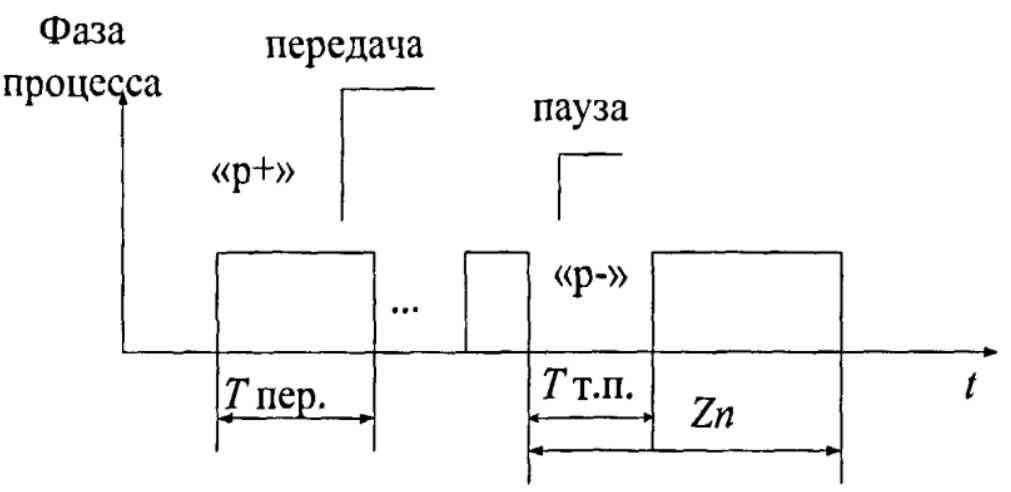

Рис. 3. Функциональная диаграмма проиесса передачи кадров в канале

Допустим, что рассчитана эффективная ширина полосы $\mathrm{h}$ в зависимости от значения качества Интернет - сервиса с для сетей с высоким коэффициентом загрузки. Каждый пользователь обеспечивается своей полосой с таким качеством, которое он заказал. Данная полоса для индивидуального пользователя являться номинальной.

Посчитаем коэффициент загрузки сети при качестве сервиса с равном 2, 10 и 70, потому что такие значения определяют низкое, среднее и высокое качество обслуживания соответственно, которое зачастую заказывают пользователи, и заметим, как будет меняется данный коэффициент, когда увеличивается длина пакета. Рассмотрим тот случай, при котором в сети Интернет - провайдера 10 пользователей.

Значения эффективной ширины полосы $\mathrm{h}$ в зависимости от значения качества Интернет - сервиса с продемонстрированы в таблице 1.

Таблица 1

\begin{tabular}{|c|c|}
\hline Качество сервиса, c & Номинальная полоса пропускания, $\mathrm{h}$, Мбит/c \\
\hline 2 & 7,340 \\
\hline 4 & 7,480 \\
\hline 6 & 7,540 \\
\hline 8 & 7,580 \\
\hline
\end{tabular}




\begin{tabular}{|c|c|}
\hline 10 & 7,610 \\
\hline 20 & 7,772 \\
\hline 30 & 7,870 \\
\hline 40 & 8,001 \\
\hline 50 & 8,100 \\
\hline 60 & 8,300 \\
\hline 70 & 8,330 \\
\hline
\end{tabular}

Время передачи пакетов зависит от номинальной пропускной способности сети и от размера пакета:

$$
T_{\text {nep. }}=\frac{L_{n}}{h}
$$

По стандарту между пакетами должна быть технологическая пауза Тт.п. в 9.6 мкс [10]. Именно поэтому период повторения пакетов составляет:

$$
Z_{n .}=T_{n e p .}+T_{m . n .}
$$

Время обработки пакетов также зависит от длины пакета. Необходимо заметить, что значение длины берется без преамбулы, потому что на канальном уровне преамбула не обрабатывается.

$$
Y_{n}=\frac{L_{n}}{h}
$$

Коэффициент загрузки сети находится из соотношения:

$$
\rho=\frac{Y_{n}}{Z_{n}}
$$

Для стабильности системы нужно, чтобы р было меньше единицы.

Посчитаем значения коэффициента загрузки сети для трех значений качества сервиса от длины пакета и результаты запишем в таблицу 2.

\begin{tabular}{|c|c|c|c|}
\hline \multicolumn{5}{|c|}{ Таблица } \\
\hline $\mathrm{L}_{\mathrm{n}}$, бит & $\rho$ при с $=2$ & $\rho$ при с $=10$ & $\rho$ при с $=70$ \\
\hline 576 & 0,792 & 0,788 & 0,781 \\
\hline 1584 & 0,919 & 0,917 & 0,913 \\
\hline 2608 & 0,950 & 0,949 & 0,946 \\
\hline 3616 & 0,964 & 0,963 & 0,961 \\
\hline 4640 & 0,972 & 0,971 & 0,969 \\
\hline 5648 & 0,977 & 0,976 & 0,975 \\
\hline 6672 & 0,980 & 0,979 & 0,977 \\
\hline 7680 & 0,983 & 0,982 & 0,981 \\
\hline 8704 & 0,985 & 0,984 & 0,984 \\
\hline 9712 & 0,986 & 0,986 & 0,985 \\
\hline 10736 & 0,988 & 0,987 & 0,987 \\
\hline 11744 & 0,989 & 0,988 & 0,988 \\
\hline 12208 & 0,989 & 0,989 & 0,988 \\
\hline
\end{tabular}

По результатам таблицы 2 построим графики. 


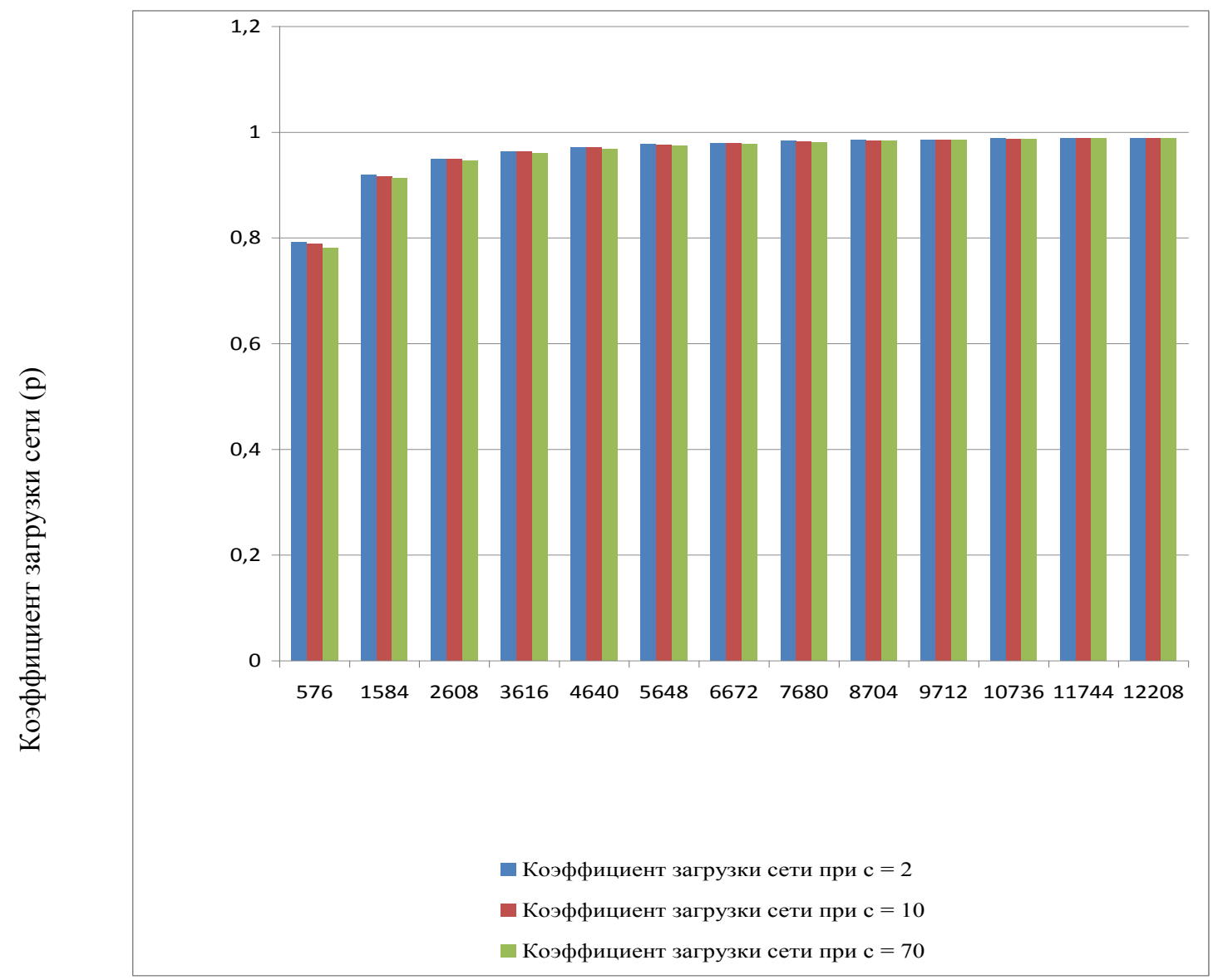

Длина пакета, бит $\left(\mathrm{L}_{\mathrm{n}}\right)$

Рис. 4. Зависимость коэффициента загрузки сети р от длины пакета Ln при разном качестве сервиса с.

Из графиков, которые построены на рисунке 4 можно заметить, что если увеличивается длина пакета, то растет и загрузка сети, а также как видно, что с увеличением качества, загрузка снижается, однако не сильно зависит от с и определяется длинной пакета.

\section{Выводы}

Подводя итоги, можно сделать следующий вывод:

1. При увеличении коэффициента загрузки сети, увеличивается и среднее время ожидания и средняя длина очереди.

2. При увеличении размера буфера, увеличивается среднее время задержки и уменьшается вероятность потерь 
1. I.O. Barabanov, N.S. Maltseva, E.A. Barabanova. Switching cell for information transmission optical systems// Conference Proceedings - 2016 International Conference on Actual Problems of Electron Devices Engineering, APEDE 2016. pp. 343-347. (SCOPUS - в процессе индексации в базе данных).

2. Elizaveta Barabanova, Natalia Maltseva, Irina Kvyatkovskaya, Ilya Beresnev. ComputerAided Design Software for Buffer Management in Rou-ters. / First conference, CIT\&DS 2015 Volgograd, Russia, September 15-17, 2015, pp. 160-169. (SCOPUS)

3. Elizaveta Barabanova, Igor Barabanov, Natalia Maltseva, Irina Kvyatkovskaya. Data Processing Algorithm for Parallel Computing. 11th Joint Conference, JCKBSE 2014, Volgograd, Russia, September 17-20, 2014, pp. 61-69, 2014. Springer International Publishing Switzerland 2014. ISSN 1865-0929. (SCOPUS)

4. Аленова О.М. Управление сетевым трафиком АТМ / О.М. Аленова // Сети, узлы и системы связи. - 1998. - №. 4, http://ccc.ru/magazine/depot/98_04/pnnt.html?0203.htm.

5. Вишнев В.М. Компьютерные сети/ В.М. Вишнев. - М.: Техносфера, 2003.- 512с

6. Гордиев В.Л. Пакетная передача речи. Часть II, Качество / В.Л. Гордиев // Сети и системы связи, - 2000 - № 12, http://www.ccc.ru/magazine/depot/00_1 2/read,html?O3 01.html

7. Клейнрок Л. Теория массового обслуживания / Л. Клейнрок. - М.: Машиностроение, 1979 - 432 c.

8. Кораблин М.А. Информатика поиска управленческих решений / М.А. Кораблин. - М.: СОЛОН - Пресс, 2003. - 191 с.

9. Корн Г., Корн Т. Справочник по математике для научных работников и инженеров / Г. Корн, Т. Корн. - М.: Наука, 1968. - 720 с.

10. Кучерявый Е.А. Управление трафиком и качество обслуживания в сети Интернет / Е.А. Кучерявый. - СПб.: Паука и техника, 2004. - 336 с.

11. Меркулова И.А. Оценка объема буфера для неотправленных данных в сетях Ethernet / И.А. Меркулова // Инфокоммуникационные технологии. - 2004. - Т.2, №4. - С. 18-22.

12. Мурыгин А.С., Палагин К. И. Прикладные методы статистического моделирования / А.С. Мурыгин, К.И. Палагин. - Л.: Машиностроение, 1986.-320 с.

13. Олифер Н., Олифер В. Базовые технологии локальных сетей / Н. Олифер, В. Олифер. Центр Информационных Технологий, 1998.

14. Семенов Ю.А. Телекоммуникационные технологии / Ю.А. Семенов. ГНЦ ИТЭФ, 2004, http://zeus.sai.msu.ru:7000/nets/semenov/

15. Хелд Г. Технологии передачи данных / Г. Хелд. - СПб.: Питер, 2003. - 720 с.

16. Шварц. М. Сети связи: протоколы, моделирование и анализ. Часть 1 / М. Шварц.-М.: Наука, 1992.-336 с. 